OPEN ACCESS

Edited by: Feng Li,

Huazhong Agricultural University,

China

Reviewed by:

Emanuela Noris,

National Research Council, Italy

Carmen Simón,

Spanish National Research Council,

Spain

*Correspondence:

Claude Bragard

claude.bragard@uclouvain.be

Gustavo Romay

gustavo.romay@uclouvain.be

Specialty section:

This article was submitted to

Virology,

a section of the journal

Frontiers in Microbiology

Received: 30 September 2016 Accepted: 06 January 2017

Published: 23 January 2017

Citation:

Romay G and Bragard C (2017) Antiviral Defenses in Plants through

Genome Editing.

Front. Microbiol. 8:47.

doi: 10.3389/fmicb.2017.00047

\section{Antiviral Defenses in Plants through Genome Editing}

\author{
Gustavo Romay* and Claude Bragard* \\ Applied Microbiology - Phytopathology, Earth and Life Institute, Université catholique de Louvain, Louvain-la-Neuve, Belgium
}

Plant-virus interactions based-studies have contributed to increase our understanding on plant resistance mechanisms, providing new tools for crop improvement. In the last two decades, RNA interference, a post-transcriptional gene silencing approach, has been used to induce antiviral defenses in plants with the help of genetic engineering technologies. More recently, the new genome editing systems (GES) are revolutionizing the scope of tools available to confer virus resistance in plants. The most explored GES are zinc finger nucleases, transcription activator-like effector nucleases, and clustered regularly interspaced short palindromic repeats/Cas9 endonuclease. GES are engineered to target and introduce mutations, which can be deleterious, via double-strand breaks at specific DNA sequences by the error-prone non-homologous recombination end-joining pathway. Although GES have been engineered to target DNA, recent discoveries of GES targeting ssRNA molecules, including virus genomes, pave the way for further studies programming plant defense against RNA viruses. Most of plant virus species have an RNA genome and at least 784 species have positive ssRNA. Here, we provide a summary of the latest progress in plant antiviral defenses mediated by GES. In addition, we also discuss briefly the GES perspectives in light of the rebooted debate on genetic modified organisms (GMOs) and the current regulatory frame for agricultural products involving the use of such engineering technologies.

Keywords: antiviral defense, CRISPR/CAS9, genome editing technologies, plant viruses, TALEN, ZFN

\section{INTRODUCTION}

Viruses are well-known to be one of the major concerns for agricultural production and food security throughout the world. It is estimated that viral agents are responsible for the half of emerging diseases reported in plants (Anderson et al., 2004). The control of plant viruses is often dependent on the use of pesticides; however, such strategy has many adverse environmental effects (Bragard et al., 2013). In many plant virus-related outbreaks, the disease management is difficult to accomplish due to the variability of factors affecting the development of the disease, such as local climate conditions, plant aging, crop varieties, vector transmission efficiency and severity of viral strains. Unlike other pathogens (i.e., fungi and bacteria), plant viruses cannot be controlled chemically and a combination of cultural practices, biosecurity measures, organismvector management and plant genetic resistance is needed to deal with the disease (Nicaise, 2014). 
The use of viral resistance factors from plants is considered one of the most important alternatives to face virus infections (Hull, 2014; Ziebell, 2016). The pioneer works on resistance to Tobacco mosaic virus in Nicotiana glutinosa led to the initial understandings on plant viral immune responses and the introgression of resistance genes from wild to cultivated plants (Mandadi and Scholthof, 2013). Over the past decades, virus resistance genes have been used to improve the most of cultivated plants and many cultivars are commercially available (Gómez et al., 2009). The main drawbacks of approaches using resistance genes are the considerable time and cost to develop a durable resistant crop variety (Kang et al., 2005).

Plants, like other eukaryotes, are able to deploy an alternative strategy to face viruses: RNA interference (RNAi). The RNAi is a biological mechanism whereby small RNA molecules, such as small interfering RNA (siRNA) or microRNA (miRNA), can regulate gene functions via post-transcriptional gene silencing. A critical breakthrough was the demonstration that doublestrand RNA (dsRNA) molecules trigger the RNAi pathway to regulate gene expression in Caenorhabditis elegans (Fire et al., 1998). This model was subsequently tested and confirmed in many other organisms. Nowadays, it is known that these dsRNAs are targeted and cleaved by the endoribonuclease Dicer producing 21 to 25-nucleotide small RNAs (siRNA or miRNA) which are bound to an Argonaute protein into the RNA-induced silencing complex (RISC) (Wilson and Doudna, 2013). The RISC is guided by the Argonaute-bound strand to a single strand RNA, perfectly complementary to the dsRNA, which is degraded or translationally inhibited (Bartel, 2009; Wilson and Doudna, 2013). In plants, dsRNA molecules from either RNA or DNA viruses may be produced and afterward processed by the host RNAi machinery to induce an antiviral response (Szittya and Burgyán, 2013). Although the RNAi triggering molecule (i.e., dsRNA) had not been discovered in the 1980s, it was known that the inhibition of gene expression could be generated by expression of antisense RNA in plant cells (Ecker and Davis, 1986). The application of this strategy to induce pathogen resistance, involving the pathogen genome itself, was called parasite-derived resistance (Sanford and Johnston, 1985), and currently referred as pathogen derive resistance (PDR). Since then, this approach has been used to derive viral resistance through transgenic expression of virus genes in plants and, in some cases, with commercial applications (Baulcombe, 1996; Simón-Mateo and García, 2011; Younis et al., 2014). However, most viruses have developed silencing suppressor mechanisms to counteract the RNAi-mediated defense of plants. Hence, an RNAi-mediated resistance in transgenic plants could be overcome by the targeted virus after inoculation with a nontarget virus possessing a silencing suppressing gene (SimónMateo and García, 2011). Besides, RNAi technology is based on knockdown gene function(s), which can be incomplete, varies between different experiments and have unpredictable off-target effects (Gaj et al., 2013). Therefore, other approaches involving stable gene modification have been gaining attention over the last decade due to their versatility to manipulate any gene from any organism (Gaj et al., 2013; Boettcher and McManus, 2015). These approaches are referred as genome editing systems (GES).
In this review, we provide insights about the latest progress on the different technologies based on GES used to control plant viruses and its perspective for a broad application in crop improvement.

\section{MECHANISMS OF GENOME EDITNG SYSTEMS}

Prior to GES development, the genetic engineering of virus resistant plants has been mainly undertaken using viral sequences, which are introduced in the genome of the susceptible plant through genetic transformation methods (Saharan et al., 2016). At least 25 viruses have been used to develop virus resistant plants by inserting the viral sequence itself (Wani and Sanghera, 2010; Saharan et al., 2016). Although several techniques for genetic transformation of plants are available, the most popular techniques are Agrobacterium infection and ballistic bombardment (Ye, 2015). Agrobacterium-mediated transformation is based on the transfer and insertion of a given DNA sequence into a plant genome by plasmids Ti (tumorinduced) or Ri (rhizogenic) from the bacterium (Gelvin, 2003). Genetic transformation trough ballistic bombardment is based on delivery of DNA-coated metal particles accelerated with a biolistic device to introduce the DNA into the target cells or tissues (Kikkert et al., 2005). Both methods have been used to develop antiviral strategies focused on PDR approach. When the complete sequence of a virus gene is inserted into the host plant genome, to interfere with the life cycle of the target virus, the PDR approach is referred as viral protein mediated resistance (Saharan et al., 2016). Within such approach the major viral proteins used are the coat protein, replicase protein, movement protein, and replication-associated protein (Prins et al., 2008). As mentioned above, the PDR approach have been also applied using small sequences from the viral genome to activate the RNAi mechanism of the host plant, via post-transcriptional gene silencing (Simón-Mateo and García, 2011).

Genome editing systems approaches against plant viruses have been mainly developed using Agrobacterium infection to introduce such systems into the plant cells for stable or unstable transformation. The applications of GES are based on the use of sequence-specific nucleases, which lead to DNA modifications by double-strand breaks (DSBs) in a targeted gene (Gaj et al., 2013; Voytas, 2013). After the DSBs DNA is repaired by two different mechanisms: (i) the non-homologous end-joining (NHEJ), in which the ends of the broken DNA are re-joined without use of a repair template, and (ii) the homologous recombination (HR) whereby two homologous DNA molecules exchange nucleotide sequences (Wyman and Kanaar, 2006). Thus, DNA modifications mediated by sequence-specific nucleases are possible in a particular genomic location (Voytas, 2013). Four major platforms for GES have been developed using sequence-specific nucleases (Figure 1), meganucleases, zinc finger nucleases (ZFNs), transcription activator like effector nucleases (TALENs) and more recently the clustered regularly interspaced short palindromic repeats (CRISPR) along with the CRISPR-associated protein 9 (Cas9) (CRISPR/Cas9). 


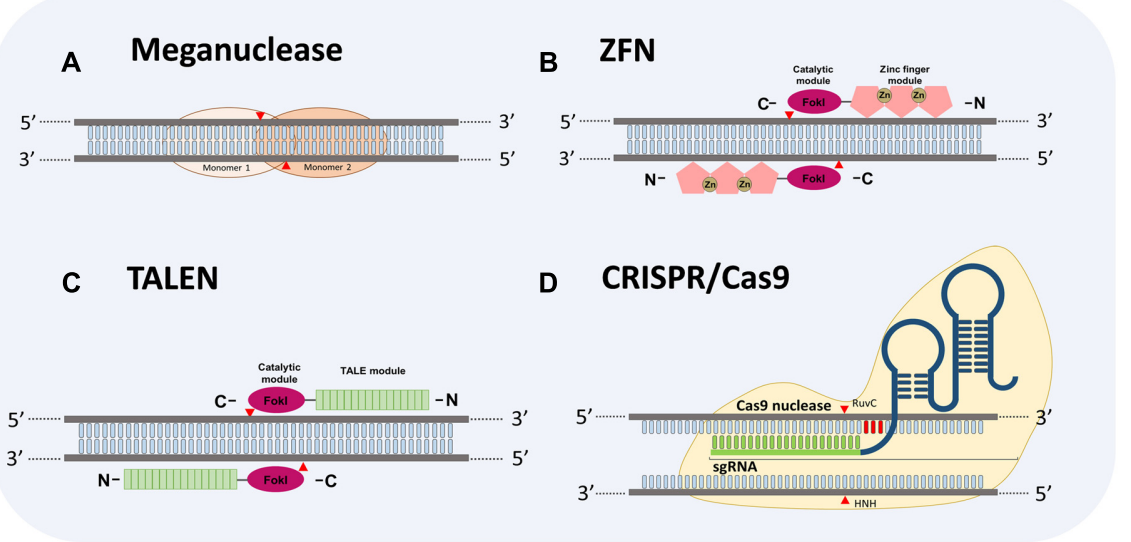

FIGURE 1 | Schematic diagram depicting four Genome Editing Systems (GES) to target DNA. (A) Homodimers structure of a meganuclease system. (B) Zinc finger nuclease (ZFN) showing two monomers bound to DNA. The ZFN contains a catalytic Fokl domain (ellipse in pink) and a zinc finger DNA-binding domain (DBD) (pentagons in rose). (C) Transcription activator-like effector nuclease (TALEN) showing two monomers bound to DNA. Like ZFN, TALEN comprises a catalytic Fokl domain (ellipse in pink). Light green rectangles represent the DNA bind domain containing the repeat variable di-residue (RVD) arrays of amino acids to recognize DNA specific sequences. (D) Clustered regularly interspaced short palindromic repeats (CRISPR) CRISPR-associated protein 9 (Cas9) (CRISPR/Cas9). Typically CRISPR/Cas9 system comprises a Cas9 protein (depicted in light gold) with two nuclease domains, referred as HuvC and HNH, and a chimeric single guide RNA (sgRNA). The sgRNA consists of a CRISPR RNA (crRNA, 21 nucleotides in light green) to direct the Cas9 protein to the complementary sequences of the DNA target and a trans-activating crRNA (RNA sequence represented in dark blue) involved in the processing of pre-crRNA into a mature crRNA. Arrowheads in red indicate cleave sites to each GES.

Meganucleases or homing endonucleases are encoded by introns and inteins that recognize DNA sequences between 12 and 42-base-pair (bp) in length, unlike restriction enzymes (Jurica and Stoddard, 1999). The meganucleases are characterized by a high specificity, even though they could tolerate single mutations in the targeted sequence (Silva et al., 2011). Due to the high specificity of meganucleases, the repertoire of targetable sequences is very limited (Pâques and Duchateau, 2007). In specific cases their utility relies on the previous insertion of the recognition site in the targeted genome to undertake a high-efficiency recombination (Carroll, 2011). To overcome this drawback, residues-specific mutations in engineering meganucleases are introduced to alter their DNA recognition sites allowing to increase the use of these proteins in gene targeting experiments, however, the production of customized meganucleases still remains too complex (Silva et al., 2011).

The second GES are the ZFNs, which are chimeric proteins created by fusing the DNA-binding domain (DBD) of a zincfinger protein with the DNA cleavage domain of the FokI restriction enzyme (Urnov et al., 2010). FokI works as a dimer and its catalytic domain cleaves the DNA sequence outside of the recognition site (Bitinaite et al., 1998). A ZFN is engineered with two monomers separated by a spacer sequence of $5-7 \mathrm{bp}$ wherein the catalytic domains of the chimeric proteins cleave each DNA brand to produce the DSB (Christian et al., 2010). An effective ZFN should contain more than three zinc-finger domains in each DNA-binding module to increase specific DNA recognition (Gaj et al., 2013).

Transcription activator-like effector nucleases is the third GES. This system is a fusion of a transcription activator-like effector (TALE) and the non-specific cleavage domain of the enzyme FokI (Cermak et al., 2011; Mahfouz et al., 2011; Pesce et al., 2015). TALEs are proteins encoded by phytopathogenic bacteria Xanthomonas spp. and delivered into the plant host cells to promote pathogen growth through manipulation of plant processes (Boch and Bonas, 2010; Schornack et al., 2013). Once TALEs are injected into the cells, they translocate to the nucleus, bind to their DNA targets and mimic host transcription factors to reprogram host gene expression (Mahfouz et al., 2011). TALE proteins are composed by an N-terminal secretion and translocation domain, a central DBD and a C-terminal transcription activation domain carrying nuclear localization signal (Schornack et al., 2013). The DNA-binding specificities of these proteins were solved by Boch et al. (2009) who showed that the DBD is an array of tandem repeat units consisting of 34 amino acids with two hypervariable amino acids at the position 12 and 13 that constitute a repeat variable diresidue (RVD). A specific amino acid arrangement in the RVD region determine a specific nucleotide recognition in the DNA target (Boch et al., 2009). Thus, this characteristic of TALEs, along with the previous knowledge on biotechnology applications of FokI enzyme, have allowed the TALEN system's design.

The fourth and most recent GES is CRISPR/Cas9, which is an RNA-guided nuclease technology. This genome editing approach is based on the CRISPR/Cas system found in most archaea and many bacteria that confers immunity against foreign DNA elements such as viruses and plasmids (Barrangou and Marraffini, 2014; Makarova et al., 2015). Barrangou et al. (2007) demonstrated that after viral challenge on several strains of Streptococcus thermophilus the bacteria are able to generate virusresistant mutants through integration of viral genome sequences 
into the CRISPR loci in association with cas genes expression. Among CRISPR/Cas systems, the CRISPR/Cas9 from S. pyogenes is the most studied model (Dominguez et al., 2016). Two elements are essential to engineer a CRISPR/Cas9 system: (i) the cas 9 protein containing two nuclease domains (RuvC and $\mathrm{HNH}$ ) that cleave both strands of the DNA target leading to DSBs and site mutations, and (ii) a guide RNA (gRNA) whose role is direct cas 9 protein to the DNA target. A gRNA is composed by two different RNA molecules: a CRISPR RNA (crRNA), which contains complementary sequences to the DNA target, and a trans-activating crRNA (tracrRNA) involved in processing of precursor crRNA molecules to a mature crRNA (Brouns et al., 2008).

A milestone in the development of CRISPR/Cas as a biotechnological tool was the engineering of a chimeric RNA containing the crRNA and tracrRNA in a single guide RNA (sgRNA), which was also able to direct Cas9 to the DNA target (Jinek et al., 2012). After such a finding, CRISPR-Cas9 technology became the most popular GES. The specificity of the CRISPR/Cas9-mediated DNA cleavage also relies on recognition of a trinucleotide sequence of DNA target referred as protospacer adjacent motif (PAM) (Sternberg et al., 2014). As showed in Figure 2, CRISPR-Cas technology is rapidly advancing and expanding its potential application not only targeting DNA molecules, like the precedent genome editing technologies, but also RNA molecules including RNA viruses.

As mentioned above, GES such as ZFN, TALEN, or CRISPRCas9 are provided of DNA-binding and catalytic domains. Meanwhile, TALE and artificial zinc finger protein (AZP) have DBDs and lack of catalytic domains. TALE and AZP can be engineered to prevent viral multiplication by blocking specific DNA sites in the viral genomes, which are essential for DNAbinding proteins of the virus and subsequent interactions with the replication machinery of host cell.

\section{GENOME TARGETING TECHNOLOGIES AND GES AGAINST PLANT VIRUSES}

In Table $\mathbf{1}$ are summarized the several genome targeting technologies that have been explored to provide potential control against plant viruses. It is important to note that the most evaluated species belong to the families Geminiviridae and Potyviridae. According to the latest report of the International Committee on Taxonomy of Viruses (ICTV), Geminiviridae and Potyviridae families represent the two largest groups of plant viruses containing 326 and 195 species, respectively (ICTV, 2015). Hence the use of these technologies to enhance plant resistance against a large number of viruses might increase significantly in the near future.

\section{Antiviral Resistance in Plants Based on Zinc Finger Technology}

The first efforts to introduce a viral inhibition factor in plants, through zinc finger technology, were carried out in the mid2000s. Sera (2005) developed an AZP in planta targeting a 19bp fragment in the intergenic region (IR) of Beet severe curly top virus (BSCTV, genus Curtovirus). BSCTV, like all members of family Geminiviridae, has an IR containing a binding site recognized by the replication initiator protein (Rep) to initiate viral replication (Rizvi et al., 2015). BSCTV replication was reduced in transgenic Arabidopsis thaliana plants carrying the AZP that was efficient to block the binding site of the BSCTV Rep (Sera, 2005). In vitro assays, using AZP technology, have also been performed to predict inhibition of Tomato yellow leaf curl virus (TYLCV, genus Begomovirus) by blocking the Rep binding site of TYLCV (Takenaka et al., 2007; Koshino-Kimura et al., 2009; Mori et al., 2013); however, its efficient application in planta remains to be confirmed. Zinc finger technology was also applied to reduce replication of Rice tungro bacilliform virus (RTBV, genus Tungrovirus) in transgenic A. thaliana plants carrying an AZP which was able to recognize and block promoter sequences of RTBV (Ordiz et al., 2010). AZP for antiviral applications have been designed to bind and block specific DNA sites that are crucial for DNA-binding proteins of viruses (Sera, 2005; Koshino-Kimura et al., 2009). Unlike AZP, the ZFN technology, for antiviral applications, involves not only the DBD but also the DNA catalytic domains of FokI restriction enzyme to introduce deleterious mutations in the viral genome, as previously explained. More recently, ZFN strategy against Tomato yellow leaf curl China virus (TYLCCNV, genus Begomovirus) was developed to target the AC1 gene of the virus that codes the Rep protein (Chen et al., 2014). In that study, agroinfiltrations of $N$. benthamiana plants with TYLCCNV infectious clone and antiviral ZFN showed a significant reduction of viral replication as compared with agroinfiltrations of the viral clone alone. Furthermore, the same ZFN developed for TYLCCNV was tested against Tobacco curly shoot virus (TbCSV), another begomovirus, showing an inhibition of the replication of the virus and, thus, suggesting a possible resistance strategy to be broadly used against begomoviruses.

\section{Antiviral Resistance in Plants Based on TALE Technology}

Recently Cheng et al. (2015) developed a TALE platform to evaluate a broad-spectrum resistance against begomoviruses. In such study, two conserved 12-nucleotide motifs among begomoviruses (into the IR and the AC1 gene, respectively) were used to engineer TALEs and, afterward, were challenged with three begomoviruses: TbCSV, Tomato leaf curl Yunnan virus (TLCYnV) and Tomato yellow leaf curl China virus (TYLCCNV). Transgenic plants of $N$. benthamiana carrying the TALEs displayed resistance to TbCSV and TYLCCNV, while the resistance to TLCYnV was partial. Although a broadspectrum approach for resistance to a virus group is desirable, it seems difficult to predict a unique TALE system to control a large group of virus like geminiviruses. TALE technologies including nuclease domains (TALEN) have not been still reported against plant viruses. For human viruses, the potential antiviral applications of TALEN have been explored for several viruses such as Human immunodeficiency virus (HIV), Hepatitis B virus (HBV), Hepatitis $\mathrm{C}$ virus (HCV), however, the generic challenges for gene therapy (e.g., adequate specificity, viral escape, efficient delivery to virus infected tissues, or limited 


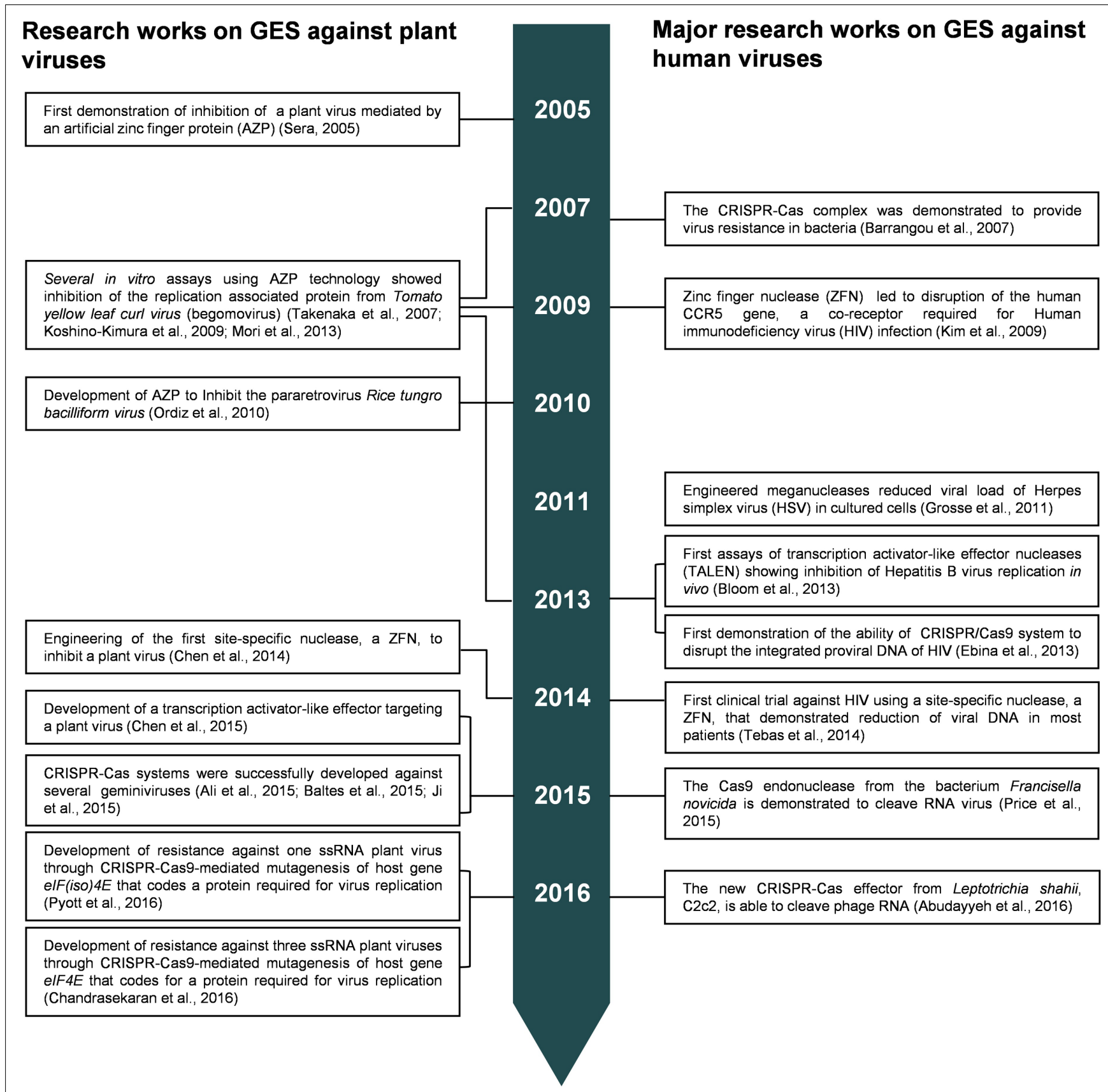

FIGURE 2 | Highlights on developments of genome editing technologies against viruses.

immune host responses) remain to be solved (Bloom et al., 2015).

\section{Antiviral Resistance in Plants Based on CRISPR-Cas Technology}

Since the advent of CRISPR-Cas system as a biotechnology tool for genome editing, many labs working with eukaryotic viruses have directed their interest on this technology due to its affordability, simplicity and efficiency as compared with precedent GES like ZFN or TALEN. Thus, many efforts are being undertaken to shed light on the potential application of CRISPRCas9 to control human viruses such as HIV, HBV, Human papillomavirus, Epstein-Barr and plant viruses (Price et al., 2016).

As showed in Table 1, four and six viruses in the families Potyviridae and Geminiviridae, respectively, have been used for developing antiviral defenses in plants, using CRISPRCas systems (Ali et al., 2015, 2016; Baltes et al., 2015; Chandrasekaran et al., 2016; Pyott et al., 2016). Interestingly, independent studies evaluating geminivirus resistance showed that the most promising sgRNAs were those targeting the IR 
TABLE 1 | Genome targeting technologies developed to confer viral resistance in plants.

\begin{tabular}{|c|c|c|c|c|c|}
\hline Genome targeting platform & Virus & Genus & Family & DNA targeted & Reference \\
\hline & $\begin{array}{l}\text { Beet curly top virus } \\
\text { (BCTV); Beet severe } \\
\text { curly top virus (BSCTV) }\end{array}$ & Curtovirus & & Viral & Ali et al., 2015; Ji et al., 2015 \\
\hline & Bean yellow dwarf virus & Mastrevirus & & Viral & Baltes et al., 2015 \\
\hline & $\begin{array}{l}\text { Cucumber vein } \\
\text { yellowing virus }\end{array}$ & Ipomovirus & Potyviridae & Host & Chandrasekaran et al., 2016 \\
\hline & $\begin{array}{l}\text { Zucchini yellow mosaic } \\
\text { virus, Papaya ringspot } \\
\text { virus, Turnip mosaic } \\
\text { virus }\end{array}$ & Potyvirus & & Host & $\begin{array}{l}\text { Chandrasekaran et al., 2016; } \\
\text { Pyott et al., } 2016\end{array}$ \\
\hline ZFN & TYLCCNV, TbCSV & Begomovirus & Geminiviridae & Viral & Chen et al., 2014 \\
\hline \multirow[t]{2}{*}{ AZP } & BSCTV, TYLCV & Begomovirus & Geminiviridae & Viral & $\begin{array}{l}\text { Sera, 2005; Takenaka et al., 2007; } \\
\text { Koshino-Kimura et al., 2009; } \\
\text { Mori et al., } 2013\end{array}$ \\
\hline & $\begin{array}{l}\text { Rice tungro bacilliform } \\
\text { virus }\end{array}$ & Tungrovirus & Caulimoviridae & Viral & Ordiz et al., 2010 \\
\hline
\end{tabular}

of these viruses (Ali et al., 2015, 2016; Baltes et al., 2015). The IR of geminiviruses contain a stem-loop structure in which an invariant nonanucleotide motif is involved in the viral replication (Hanley-Bowdoin et al., 2000). Baltes et al. (2015) observed that sgRNAs designed near to the stem-loop structure of Bean yellow dwarf virus were less efficient to generate insertions/deletions (indels), suggesting a possible interference of the secondary structure on the sgRNA-Cas9 cleavage. Despite that, viral load was reduced probably by blocking of the Rep binding site (Baltes et al., 2015). Furthermore, Ali et al. (2015) engineered a sgRNACas9 that was efficient to target the IR of TYLCV and also that of other geminiviruses like Beet curly top virus and Merremia mosaic virus. More recently, sgRNA-Cas9 targeting the IRs and the coat protein genes of the TYLCV and Cotton leaf curl Kokhran virus showed that CRISPR-Cas9 directed to coding sequences can generate viral variants which are able to replicate and spread in the plants, while CRISPR-Cas9 directed to noncoding intergenic sequences produced viral interference and a low recovery of mutated viral variants (Ali et al., 2016). One of the most interesting feature of CRISPR-Cas9 system is its flexibility to assemble multiple gRNA modules for targeting several genes simultaneously (Xing et al., 2014; Xie et al., 2015). Baltes et al. (2015) showed that a CRISPR-Cas9 system containing two gRNA modules targeting the same viral genome was more effective to reduce the infection than their relative gRNA delivered in separated constructs.

Given that GES target DNA sequences, these technologies seem to be mainly suitable for plant DNA viruses. However, an interesting CRISPR-Cas9 approach has been successfully used to develop resistant plants against RNA viruses, demonstrating that CRISPR-Cas9 system is a promising and powerful tool to be considered in the near future for crop improvement programs. Two recent studies showed the CRISPR-Cas9-mediated disruption of plant genes encoding eukaryotic translation initiation factors in cucumber and A. thaliana (Chandrasekaran et al., 2016; Pyott et al., 2016, respectively). Interactions between eukaryotic translation initiation factors $4 \mathrm{E}$ (eIF4E) or its isoform eIF(iso) $4 \mathrm{E}$ and the viral genome-linked protein (VPg) of potyviruses are required for the virus infection (Robaglia and Caranta, 2006). Natural resistance to potyviruses are generally associated with mutations of host eIF4E or eIF(iso) $4 \mathrm{E}$ that hamper their interaction with the VPg protein (Estevan et al., 2014; Sanfaçon, 2015). Chandrasekaran et al. (2016) used CRISPR-Cas9 systems to mutate the eIF4E gene in cucumber plants conferring resistance to the ipomovirus Cucumber vein yellowing virus, and to the potyviruses Zucchini yellow mosaic virus and Papaya ring spot virus. Similarly, Pyott et al. (2016) developed another CRISPR-Cas9 construct to introduce site specific-mutations in the $\operatorname{IF}$ (iso) $4 E$ gene of A. thaliana, which were efficient to confer resistance to the potyvirus Turnip mosaic virus (TuMV) In the light of these studies, CRISPR-Cas9 systems could be developed to target host genes coding for other members in the family of plant translation factors such as eIF4G, eIF(iso)GE, eIF4A-like helicases, eIF3, eEF1A, and eEF1B that are also identified to interplay with protein and viral RNAs (Nicaise, 2014; Sanfaçon, 2015). 


\section{THE PLANT VIRUS RANGE THAT GES CAN TARGET}

Genome editing systems are known to bind to double-stranded DNA (dsDNA) and subsequently introduce a DSB in a sequencespecific manner. Hence, the first studies using genome targeting or genome editing platforms for plant viruses aimed to control DNA viruses (Table 1). Although the members of the plant virus families Geminiviridae and Nanoviridae are composed of single-stranded DNA (ssDNA), they also contain replicative intermediate forms of dsDNA which can be targeted by GES. The other plant virus family possessing DNA genomes is Caulimoviridae. Unlike geminiviruses and nanoviruses, the caulimoviruses have a dsDNA genome. Currently, there are 432 virus species that belong to the DNA virus families Geminiviridae, Nanoviridae, and Caulimoviridae (ICTV, 2015). Others viruses in the families Metaviridae and Pseudoviridae that infect plants could be directly targeted by GES. Metaviruses and pseudoviruses are reverse transcribing RNA viruses. Although their genomes are single-stranded RNA (ssRNA), they possess replicative dsDNA forms (Boeke et al., 2012; Eickbush et al., 2012), being good candidates to be targeted by GES. In fact, the reverse transcribing RNA virus HIV has already been subjected to GES by targeting its replicative DNA forms known as provirus (Price et al., 2016).

The majority of plant viruses have RNA genomes. More specifically, 836 out of 1268 species recognized by the ICTV are RNA viruses (ICTV, 2015). Although all GES are able to bind DNA molecules, it was shown that Cas9 protein is able to bind and cleave ssRNA when using specially designed PAMpresenting oligonucleotides (O'Connell et al., 2014). Therefore, the development of an RNA-targeting CRISPR/Cas9 complex offers a promising platform to control RNA viruses. Interestingly, two recent discoveries showed that CRISPR-Cas system can directly interfere with RNA virus infections. In the first study, Price et al. (2015) developed a CRISPR-Cas9 system to target HCV (ssRNA virus) using a new variant of Cas9 endonuclease, called FnCas9, capable to cleave ssRNA molecules. FnCas9 is a Cas protein from the bacterium Francisella novicida, which is able to repress a endogenous mRNA (Sampson et al., 2013). In the second study, a new Cas protein from the bacterium Leptotrichia shahii was characterized and named C2c2. This protein contains two HEPN (Higher Eukaryotic and Prokaryotic nucleotide-binding) RNase domains (Shmakov et al., 2015). In L. shahii $\mathrm{C} 2 \mathrm{c} 2$ provides resistance to an RNA phage and it was recently demonstrated to be guided by a single crRNA and programmable against ssRNA (Abudayyeh et al., 2016). Taking into account that 784 out of 1268 plant virus species possesses ssRNA, these discoveries could play a prominent role, in the near future, to enhance the current tools for plant virus control.

\section{APPLICATIONS OF GES BEYOND PLANT VIRUS CONTROL IN AGRICULTURE}

The great success of the RNAi technology was based on the ability to modulate gene expression by post-transcriptional gene silencing mechanisms whereby the role of many genes has been unveiled. GES are not only able to modulate gene expression, but also are useful to introduce nucleotide modifications into the genome of almost every organism. Hence, gene editing technologies seem to have no limits on their applications. Such applications have been extensively reviewed (Gaj et al., 2013; Boettcher and McManus, 2015; Govindan and Ramalingam, 2016; Steinert et al., 2016). In agriculture, the applications of GES have been explored for many purposes in addition to plant virus control. For example, a meganuclease system was developed to confer herbicide tolerance in cotton lines (D'Halluin et al., 2013). Herbicide resistant plants were also generated using zinc finger technologies to target tobacco acetolactate synthase genes that are involved in resistance to imidazolinone and sulphonylurea herbicides (Townsend et al., 2009). TALENs have been successfully used to inhibit the vacuolar invertase gene in potato, which is associated with the accumulation of reducing sugars and high levels of acrylamide, a potential carcinogen, in tubers (Clasen et al., 2016). TALEN and CRISPR/Cas9 systems were demonstrated to target several genes implicated with the phytic acid production in maize seeds (Liang et al., 2014). Phytic acid is a major storage for phosphorus and mineral cations in several crops and it is poorly digested by monogastric animals (Shi et al., 2003). In wheat, TALENs and CRISPR/Cas9 were also used to confer fungi resistant in wheat lines by disrupting of the mildew locus $\mathrm{O}(M L O)$ gene, which is related with mildew powder susceptibility (Wang et al., 2014). Besides GES targeting plant genomes, CRISPR/Cas9 system was used to inhibit genes encoding polyphenol oxidase that causes browning in common white mushroom (Agaricus bisporus) (Waltz, 2016). In general, many successful examples of GES targeting crops have demonstrated the broad spectrum of applications that exhibit these technologies in agriculture beyond plant virus control.

\section{GES-MEDIATED PLANT VIRUS DEFENSES VIS-À-VIS GMO REGULATIONS}

The insights on the scope of GES is rapidly advancing throughout the scientific community. For virologists and plant breeders, genome editing technologies is offering an encouraging approach to circumvent labor-intensive and time-consuming methods used in conventional genetic engineering and traditional breeding techniques. Nevertheless, one of the major hurdles of the GES approaches is the public perception in which a product obtained from these technologies is considered as a genetic modified organism (GMO). The GMO definition according to the Cartagena Protocol on Biosafety and the European Union was mainly conceived to distinguish products obtained by conventional plant breeding technologies and those obtained by recombinant DNA technologies (Sprink et al., 2016). Development of transgenic plants implies the transfer of foreign DNA into host cells. For example, several cases of virus-resistant plants have been generated by insertion of partial sequences from viral genomes based on RNAi technology (Simón-Mateo and García, 2011). Unlike, some genome editing approaches allow the insertion of point mutations in the genome of recipient species 
and afterward it is possible the removal of the encoding sequences of the programmable nucleases. Indeed, Chandrasekaran et al. (2016) introduced mutations in the factor eIF4E of cucumber plants using the CRISPR/Cas9 system, to induce resistance to potyviruses, and subsequently the gene encoding the GES was removed by breeding, leading to transgene-free generations. Likewise, Pyott et al. (2016) generated TuMV resistant plants of $A$. thaliana lacking the CRISPR/Cas9 system after two generations. Insertion of point mutations are also feasible using mutagenic agents. For example, using the technique TILLING (targeting induced local lesions in genomes) point mutations in tomato eIF4 were induced by ethyl methanesulfonate to confer immunity to two potyviruses (Piron et al., 2010). Besides this, crop improvement derivate by mutagenic agents are not considered as GMO due to the lack of foreign DNA. Thus, some genome editing approaches are considered to generate nontransgenic plants (plant without foreign DNA). However, the controversy whether the products generated by these type of technologies should be considered GMOs or not still remains (Sprink et al., 2016). In another example of transgene-free plants modified by GES, a preassembled CRISPR/Cas 9 complex was successfully delivered to induce mutations into protoplasts of A. thaliana, tobacco, lettuce and rice producing regenerated plants with the expected mutations and without foreign DNA (Woo et al., 2015). Such approach could be useful to eliminate pararetroviruses that are able to integrate their genomes in the host genome. One of the most important cases is the banana streak viruses (BSVs), because the cultivated banana species are only reproduced by vegetative propagation and BSVs remain inserted into genome indefinitely. Along with BSVs, Banana bunchy top virus (BBTV, family Nanoviridae) are the most economically important viruses for banana production worldwide (Rybicki, 2015; Mukwa et al., 2016). Interestingly, BBTV is a DNA virus that could be directly targeted using the same transgene-free GES approach.

Currently there is a growing worldwide debate about to how to regulate research and use of plant produced with the novel genome editing technologies (Sprink et al., 2016). In the meantime, contrasting scenarios are offered. For example, on the one hand, in the European Union, many research groups are directly concerned and waiting for the European Commission' answer regarding the legal status of gene-edited plants and whether these plants should be regulated as GMOs (Abbott, 2015). On the other hand, in the USA, several geneedited products have already been deregulated, including the first CRISPR-edited organism, a gene-edited mushroom (Wolt et al., 2015; Waltz, 2016). Overall, regardless of the swift progresses on genome editing technologies that are expanding our boundaries on plant virus control, other factors such as regulatory frameworks, biosafety and public perception of geneedited organisms are also important to take into account. "At the

\section{REFERENCES}

Abbott, A. (2015). Europe's genetically edited plants stuck in legal limbo. Nature 528, 319-320. doi: 10.1038/528319a dawn of the recombinant DNA era, the most important lesson learned was that public trust in science ultimately begins with and requires ongoing transparency and open discussion" (Baltimore et al., 2015).

\section{CONCLUDING REMARKS}

Altogether, genome editing technologies are revolutionizing the current tools for crop improvement programs, including the antiviral arsenal of plants. Nowadays, the proof of concept of zinc finger (including AZP and ZFN), Tale and CRISPR-Cas9 technologies against plant viruses have been done for at least 14 different species, mainly in the families Geminiviridae and Potyviridae. Among these technologies, CRISPR-Cas9 has been already explored for most of the viruses tested, despite the fact that it is the more recently developed GES. This fact might be explained by the simplicity of CRISPR-Cas9 designing, which can be adopted by standard biotechnological laboratories. However, off-targets effects (possible breaks in non-targeted DNA sites) continue as a major concern for application of CRISPR-Cas9 technology. A next generation sequencing (NGS) approach can be useful to provide a compelling profile of off-target cleavage sites for a given GES (Gaj et al., 2013). Likewise, NGS approaches will be useful to gain insights on pathosystems involving CRISPRCas9-edited plants and targeted viruses (Hadidi et al., 2016). Beyond the debate on regulation of GES-edited plant products, the use of GESs to induce antiviral defenses raises the question on durable resistance mediated by these technologies and the generation of challenging viral isolates. Although promising, the genome editing studies aiming to generate plant virus resistance have been carried out just to evaluate resistance against specific viruses. However, further studies addressing a larger spectrum of viral isolates in a same species and longer period of viral exposition are needed to better understand the durable resistance mediated by GES and the possible mechanisms deployed by some viral isolates to overcome the induced antiviral defenses.

\section{AUTHOR CONTRIBUTIONS}

GR wrote the draft version of manuscript and $\mathrm{CB}$ reviewed the manuscript providing substantial contributions. Both authors read and approved the final version of the work.

\section{FUNDING}

GR was supported by Move-In Louvain fellowship of Université catholique de Louvain.

Abudayyeh, O. O., Gootenberg, J. S., Konermann, S., Joung, J., Slaymaker, I. M., Cox, D. B., et al. (2016). C2c2 is a single-component programmable RNAguided RNA-targeting CRISPR effector. Science 353, aaf5573. doi: 10.1126/ science.aaf5573 
Ali, Z., Abulfaraj, A., Idris, A., Ali, S., Tashkandi, M., and Mahfouz, M. M. (2015). CRISPR/Cas9-mediated viral interference in plants. Genome Biol. 16:238. doi: 10.1186/s13059-015-0799-6

Ali, Z., Ali, S., Tashkandi, M., Zaidi, S. S., and Mahfouz, M. M. (2016). CRISPR/Cas9-mediated immunity to geminiviruses: differential interference and evasion. Sci. Rep. 6:26912. doi: 10.1038/srep26912

Anderson, P. K., Cunningham, A. A., Patel, N. G., Morales, F. J., Epstein, P. R., and Daszak, P. (2004). Emerging infectious diseases of plants: pathogen pollution, climate change and agrotechnology drivers. Trends Ecol. Evol. 19, 535-544. doi: $10.1016 /$ j.tree.2004.07.021

Baltes, N. J., Hummel, A. W., Konecna, E., Cegan, C., Bruns, A. N., Bisaro, D. M., et al. (2015). Conferring resistance to geminiviruses with the CRISPR-Cas prokaryotic immune system. Nat. Plants 1:15145. doi: 10.1038/nplants.2015.145

Baltimore, D., Berg, P., Botchan, M., Carroll, D., Charo, R., Church, G., et al. (2015). Biotechnology. A prudent path forward for genomic engineering and germline gene modification. Science 348, 36-38. doi: 10.1126/science.aab 1028

Barrangou, R., Fremaux, C., Deveau, H., Richards, M., Boyaval, P., Moineau, S., et al. (2007). CRISPR provides acquired resistance against viruses in prokaryotes. Science 315, 1709-1712. doi: 10.1126/science. 1138140

Barrangou, R., and Marraffini, L. A. (2014). CRISPR-Cas systems: prokaryotes upgrade to adaptive immunity. Mol. Cell 54, 234-244. doi: 10.1016/j.molcel. 2014.03.011

Bartel, D. P. (2009). MicroRNAs: target recognition and regulatory functions. Cell 136, 215-233. doi: 10.1016/j.cell.2009.01.002

Baulcombe, D. C. (1996). Mechanisms of pathogen-derived resistance to viruses in transgenic plants. Plant Cell 8, 1833-1844. doi: 10.1105/tpc.8.10.1833

Bitinaite, J., Wah, D. A., Aggarwal, A. K., and Schildkraut, I. (1998). FokI dimerization is required for DNA cleavage. Proc. Natl. Acad. Sci. U.S.A. 95, 10570-10575. doi: 10.1073/pnas.95.18.10570

Bloom, K., Mussolino, C., and Arbuthnot, P. (2015). Transcription activator-like effector (TALE) nucleases and repressor TALEs for antiviral gene therapy. Curr. Stem Cell Rep. 1, 1-8. doi: 10.1007/s40778-014-0008-7

Boch, J., and Bonas, U. (2010). Xanthomonas AvrBs3 family-type III effectors: discovery and function. Annu. Rev. Phytopathol. 48, 419-436. doi: 10.1146/ annurev-phyto-080508-081936

Boch, J., Scholze, H., Schornack, S., Landgraf, A., Hahn, S., Kay, S., et al. (2009). Breaking the code of DNA binding specificity of TAL-type III effectors. Science 326, 1509-1512. doi: 10.1126/science.1178811

Boeke, J. D., Eickbush, T., Sandmeyer, S. B., and Voytas, D. F. (2012). "Pseudoviridae," in Virus Taxonomy: Ninth Report of the International Committee on Taxonomy of Viruses, eds A. M. Q. King, M. J. Adams, E. B. Carstens, and E. J. Lefkowitz (Amsterdam: Elsevier/Academic Press), 467-476.

Boettcher, M., and McManus, M. T. (2015). Choosing the right tool for the job: RNAi, TALEN, or CRISPR. Mol. Cell 58, 575-585. doi: 10.1016/j.molcel.2015. 04.028

Bragard, C., Caciagli, P., Lemaire, O., Lopez-Moya, J. J., MacFarlane, S., Peters, D., et al. (2013). Status and prospects of plant virus control through interference with vector transmission. Annu. Rev. Phytopathol. 51, 177-201. doi: 10.1146/ annurev-phyto-082712-102346

Brouns, S. J., Jore, M. M., Lundgren, M., Westra, E. R., Slijkhuis, R. J., Snijders, A. P., et al. (2008). Small CRISPR RNAs guide antiviral defense in prokaryotes. Science 321, 960-964. doi: 10.1126/science.1159689

Carroll, D. (2011). Genome engineering with zinc-finger nucleases. Genetics 188, 773-782. doi: 10.1534/genetics.111.131433

Cermak, T., Doyle, E. L., Christian, M., Wang, L., Zhang, Y., Schmidt, C., et al. (2011). Efficient design and assembly of custom TALEN and other TAL effectorbased constructs for DNA targeting. Nucleic Acids Res. 39:e82. doi: 10.1093/nar/ gkr218

Chandrasekaran, J., Brumin, M., Wolf, D., Leibman, D., Klap, C., Pearlsman, M., et al. (2016). Development of broad virus resistance in non-transgenic cucumber using CRISPR/Cas9 technology. Mol. Plant Pathol. 17, 1140-1153. doi: $10.1111 / \mathrm{mpp} .12375$

Chen, W., Qian, Y., Wu, X., Sun, Y., Wu, X., and Cheng, X. (2014). Inhibiting replication of begomoviruses using artificial zinc finger nucleases that target viral-conserved nucleotide motif. Virus Genes 48, 494-501. doi: 10.1007/ s11262-014-1041-4
Cheng, X., Li, F., Cai, J., Chen, W., Zhao, N., Sun, Y., et al. (2015). Artificial TALE as a convenient protein platform for engineering broad-spectrum resistance to begomoviruses. Viruses 7, 4772-4782. doi: 10.3390/v7082843

Christian, M., Cermak, T., Doyle, E. L., Schmidt, C., Zhang, F., Hummel, A., et al. (2010). Targeting DNA double-strand breaks with TAL effector nucleases. Genetics 186, 757-761. doi: 10.1534/genetics.110.120717

Clasen, B. M., Stoddard, T. J., Luo, S., Demorest, Z. L., Li, J., Cedrone, F., et al. (2016). Improving cold storage and processing traits in potato through targeted gene knockout. Plant Biotechnol. J. 14, 169-176. doi: 10.1111/pbi.12370

D’Halluin, K., Vanderstraeten, C., Van Hulle, J., Rosolowska, J., Van Den Brande, I., Pennewaert, A., et al. (2013). Targeted molecular trait stacking in cotton through targeted double-strand break induction. Plant Biotechnol. J. 11, 933941. doi: 10.1111/pbi.12085

Dominguez, A. A., Lim, W. A., and Qi, L. (2016). Beyond editing: repurposing CRISPR-Cas9 for precision genome regulation and interrogation. Nat. Rev. Mol. Cell Biol. 17, 5-15. doi: 10.1038/nrm.2015.2

Ebina, H., Misawa, N., Kanemura, Y., and Koyanagi, Y. (2013). Harnessing the CRISPR/Cas9 system to disrupt latent HIV-1 provirus. Sci. Rep. 3:2510. doi: $10.1038 /$ srep02510

Ecker, J. R., and Davis, R. W. (1986). Inhibition of gene expression in plant cells by expression of antisense RNA. Proc. Natl. Acad. Sci. U.S.A. 83, 5372-5376. doi: $10.1073 /$ pnas.83.15.5372

Eickbush, T., Boeke, J. D., Sandmeyer, S. B., and Voytas, D. F. (2012). “Metaviridae," in Virus Taxonomy: Ninth Report of the International Committee on Taxonomy of Viruses, eds A. M. Q. King, M. J. Adams, E. B. Carstens, and E. J. Lefkowitz (Amsterdam: Elsevier/Academic Press), 456-466.

Estevan, J., Maréna, A., Callot, C., Lacombe, S., Moretti, A., Caranta, C., et al. (2014). Specific requirement for translation initiation factor $4 \mathrm{E}$ or its isoform drives plant host susceptibility to Tobacco etch virus. BMC Plant Biol. 14:67. doi: 10.1186/1471-2229-14-67

Fire, A., Xu, S., Montgomery, M. K., Kostas, S. A., Driver, S. E., and Mello, C. C. (1998). Potent and specific genetic interference by double-stranded RNA in Caenorhabditis elegans. Nature 391, 806-811. doi: 10.1038/35888

Gaj, T., Gersbach, C. A., and Barbas, C. F. (2013). ZFN, TALEN, and CRISPR/Casbased methods for genome engineering. Trends Biotechnol. 31, 397-405. doi: 10.1016/j.tibtech.2013.04.004

Gelvin, S. B. (2003). Agrobacterium-mediated plant transformation: the biology behind the "Gene-Jockeying" tool. Microbiol. Mol. Biol. Rev. 67, 16-37. doi: 10.1128/MMBR.67.1.16-37.2003

Gómez, P., Rodríguez-Hernández, A. M., Moury, B., and Aranda, M. A. (2009). Genetic resistance for the sustainable control of plant virus disease: breeding, mechanisms and durability. Eur. J. Plant Pathol. 125, 1-22. doi: 10.1007/s10658009-9468-5

Govindan, G., and Ramalingam, S. (2016). Programmable site-specific nucleases for targeted genome engineering in higher eukaryotes. J. Cell Physiol. 231, 2380-2392. doi: 10.1002/jcp.25367

Grosse, S., Huot, N., Mahiet, C., Arnould, S., Barradeau, S., Clerre, D. L., et al. (2011). Meganuclease-mediated inhibition of HSV1 infection in cultured cells. Mol. Ther. 19, 694-702. doi: 10.1038/mt.2010.302

Hadidi, A., Flores, R., Candresse, T., and Barba, M. (2016). Next-generation sequencing and genome editing in plant virology. Front. Plant Sci. 7:1325. doi: 10.3389/fmicb.2016.01325

Hanley-Bowdoin, L., Settlage, S. B., Orozco, B. M., Nagar, S., and Robertson, D. (2000). Geminiviruses: models for plant DNA replication, transcription, and cell cycle regulation. Crit. Rev. Biochem. Mol. Biol. 35, 105-140.

Hull, R. (2014). Plant Virology. San Diego, CA: Elsevier Academic Press.

ICTV (2015). ICTV Master Species List 2015 v1. Available at: https:// talk.ictvonline.org/files/master-species-lists/m/msl/5945 [accessed August 20, 2014].

Ji, X., Zhang, H., Zhang, Y., Wang, Y., and Gao, C. (2015). Establishing a CRISPRCas-like immune system conferring DNA virus resistance in plants. Nat. Plants 1:15144. doi: $10.1038 /$ nplants.2015.144

Jinek, M., Chylinski, K., Fonfara, I., Hauer, M., Doudna, J. A., and Charpentier, E. (2012). A programmable dual-RNA-guided DNA endonuclease in adaptive bacterial immunity. Science 337, 816-821. doi: 10.1126/science.1225829

Jurica, M. S., and Stoddard, B. L. (1999). Homing endonucleases: structure, function and evolution. Cell Mol. Life Sci. 55, 1304-1326. doi: 10.1007/ s000180050372 
Kang, B. C., Yeam, I., and Jahn, M. M. (2005). Genetics of plant virus resistance. Annu. Rev. Phytopathol. 43, 581-621. doi: 10.1146/annurev.phyto.43.011205. 141140

Kikkert, J. R., Vidal, J. R., and Reisch, B. I. (2005). Stable transformation of plant cells by particle bombardment/biolistics. Methods Mol. Biol. 286, 61-78.

Kim, H. J., Lee, H. J., Kim, H., Cho, S. W., and Kim, J. S. (2009). Targeted genome editing in human cells with zinc finger nucleases constructed via modular assembly. Genome Res. 19, 1279-1288. doi: 10.1101/gr.089417.108

Koshino-Kimura, Y., Takenaka, K., Domoto, F., Ohashi, M., Miyazaki, T., Aoyama, Y., et al. (2009). Construction of plants resistant to TYLCV by using artificial zinc-finger proteins. Nucleic Acids Symp. Ser. (Oxf.) 53, 281-282. doi: 10.1093/nass/nrp141

Liang, Z., Zhang, K., Chen, K., and Gao, C. (2014). Targeted mutagenesis in Zea mays using TALENs and the CRISPR/Cas system. J. Genet. Genomics 41, 63-68. doi: 10.1016/j.jgg.2013.12.001

Mahfouz, M. M., Li, L., Shamimuzzaman, M., Wibowo, A., Fang, X., and Zhu, J. K. (2011). De novo-engineered transcription activator-like effector (TALE) hybrid nuclease with novel DNA binding specificity creates double-strand breaks. Proc. Natl. Acad. Sci. U.S.A. 108, 2623-2628. doi: 10.1073/pnas.1019533108

Makarova, K. S., Wolf, Y. I., Alkhnbashi, O. S., Costa, F., Shah, S. A., Saunders, S. J., et al. (2015). An updated evolutionary classification of CRISPR-Cas systems. Nat. Rev. Microbiol. 13, 722-736. doi: 10.1038/nrmicro3569

Mandadi, K. K., and Scholthof, K. B. (2013). Plant immune responses against viruses: How does a virus cause disease? Plant Cell 25, 1489-1505. doi: 10.1105/ tpc. 113.111658

Mori, T., Takenaka, K., Domoto, F., Aoyama, Y., and Sera, T. (2013). Inhibition of binding of tomato yellow leaf curl virus rep to its replication origin by artificial zinc-finger protein. Mol. Biotechnol. 54, 198-203. doi: 10.1007/s12033012-9552-5

Mukwa, L. F., Gillis, A., Vanhese, V., Romay, G., Galzi, S., Laboureau, N., et al. (2016). Low genetic diversity of Banana bunchy top virus, with a sub-regional pattern of variation, in Democratic Republic of Congo. Virus Genes 52, 900-905. doi: $10.1007 /$ s11262-016-1383-1

Nicaise, V. (2014). Crop immunity against viruses: outcomes and future challenges. Front. Plant Sci. 5:660. doi: 10.3389/fpls.2014.00660

O’Connell, M. R., Oakes, B. L., Sternberg, S. H., East-Seletsky, A., Kaplan, M., and Doudna, J. A. (2014). Programmable RNA recognition and cleavage by CRISPR/Cas9. Nature 516, 263-266. doi: 10.1038/nature13769

Ordiz, M. I., Magnenat, L., Barbas, C. F., and Beachy, R. N. (2010). Negative regulation of the RTBV promoter by designed zinc finger proteins. Plant Mol. Biol. 72, 621-630. doi: 10.1007/s11103-010-9600-0

Pâques, F., and Duchateau, P. (2007). Meganucleases and DNA double-strand break-induced recombination: perspectives for gene therapy. Curr. Gene Ther. 7, 49-66. doi: 10.2174/156652307779940216

Pesce, C., Bolot, S., Cunnac, S., Portier, P., Fischer-Le Saux, M., Jacques, M. A., et al. (2015). High-quality draft genome sequence of the Xanthomonas translucens pv. cerealis pathotype strain CFBP 2541. Genome Announc. 3:e1574-14. doi: 10.1128/genomeA.01574-14

Piron, F., Nicolaï, M., Minoïa, S., Piednoir, E., Moretti, A., Salgues, A., et al. (2010). An induced mutation in tomato eIF4E leads to immunity to two potyviruses. PLoS ONE 5:e11313. doi: 10.1371/journal.pone.0011313

Price, A. A., Grakoui, A., and Weiss, D. S. (2016). Harnessing the prokaryotic adaptive immune system as a eukaryotic antiviral defense. Trends Microbiol. 24, 294-306. doi: 10.1016/j.tim.2016.01.005

Price, A. A., Sampson, T. R., Ratner, H. K., Grakoui, A., and Weiss, D. S. (2015). Cas9-mediated targeting of viral RNA in eukaryotic cells. Proc. Natl. Acad. Sci. U.S.A. 112, 6164-6169. doi: 10.1073/pnas.142234 0112

Prins, M., Laimer, M., Noris, E., Schubert, J., Wassenegger, M., and Tepfer, M. (2008). Strategies for antiviral resistance in transgenic plants. Mol. Plant Pathol. 9, 73-83. doi: 10.1111/j.1364-3703.2007.00447.x

Pyott, D. E., Sheehan, E., and Molnar, A. (2016). Engineering of CRISPR/Cas9mediated potyvirus resistance in transgene-free Arabidopsis plants. Mol. Plant Pathol. 17, 1276-1288. doi: 10.1111/mpp.12417

Rizvi, I., Choudhury, N. R., and Tuteja, N. (2015). Insights into the functional characteristics of geminivirus rolling-circle replication initiator protein and its interaction with host factors affecting viral DNA replication. Arch. Virol. 160, 375-387. doi: 10.1007/s00705-014-2297-7
Robaglia, C., and Caranta, C. (2006). Translation initiation factors: a weak link in plant RNA virus infection. Trends Plant Sci. 11, 40-45. doi: 10.1016/j.tplants. 2005.11.004

Rybicki, E. P. (2015). A Top Ten list for economically important plant viruses. Arch. Virol. 160, 17-20. doi: 10.1007/s00705-014-2295-9

Saharan, V., Jain, D., Pareek, S., Ajay, P., Kumaraswamy, R. V., Kumari Jakhar, S., et al. (2016). "Viral, fungal and bacterial disease resistance in transgenic plants," in Advances in Plant Breeding Strategies: Agronomic, Abiotic and Biotic Stress Traits, eds J. M. Al-Khayri, S. M. Jain, and D. V. Johnson (Cham: Springer International Publishing), 627-656.

Sampson, T. R., Saroj, S. D., Llewellyn, A. C., Tzeng, Y. L., and Weiss, D. S. (2013). CRISPR/Cas system mediates bacterial innate immune evasion and virulence. Nature 497, 254-257. doi: 10.1038/nature12048

Sanfaçon, H. (2015). Plant Translation Factors and Virus Resistance. Viruses 7, 3392-3419. doi: 10.3390/v7072778

Sanford, J. C., and Johnston, S. A. (1985). The concept of parasite-derived resistance-Deriving resistance genes from the parasite's own genome. J. Theor. Biol. 113, 395-405. doi: 10.1016/S0022-5193(85)80234-4

Schornack, S., Moscou, M. J., Ward, E. R., and Horvath, D. M. (2013). Engineering plant disease resistance based on TAL effectors. Annu. Rev. Phytopathol. 51, 383-406. doi: 10.1146/annurev-phyto-082712-102255

Sera, T. (2005). Inhibition of virus DNA replication by artificial zinc finger proteins. J. Virol. 79, 2614-2619. doi: 10.1128/JVI.79.4.2614-2619.2005

Shi, J., Wang, H., Wu, Y., Hazebroek, J., Meeley, R. B., and Ertl, D. S. (2003). The maize low-phytic acid mutant lpa2 is caused by mutation in an inositol phosphate kinase gene. Plant Physiol. 131, 507-515. doi: 10.1104/pp.014258

Shmakov, S., Abudayyeh, O. O., Makarova, K. S., Wolf, Y. I., Gootenberg, J. S., Semenova, E., et al. (2015). Discovery and functional characterization of diverse class 2 CRISPR-cas systems. Mol. Cell 60, 385-397. doi: 10.1016/j.molcel.2015. 10.008

Silva, G., Poirot, L., Galetto, R., Smith, J., Montoya, G., Duchateau, P., et al. (2011). Meganucleases and other tools for targeted genome engineering: perspectives and challenges for gene therapy. Curr. Gene Ther. 11, 11-27. doi: 10.2174/ 156652311794520111

Simón-Mateo, C., and García, J. A. (2011). Antiviral strategies in plants based on RNA silencing. Biochim. Biophys. Acta 1809, 722-731. doi: 10.1016/j.bbagrm. 2011.05.011

Sprink, T., Eriksson, D., Schiemann, J., and Hartung, F. (2016). Regulatory hurdles for genome editing: process- vs. product-based approaches in different regulatory contexts. Plant Cell Rep. 35, 1493-1506. doi: 10.1007/s00299-0161990-2

Steinert, J., Schiml, S., and Puchta, H. (2016). Homology-based double-strand break-induced genome engineering in plants. Plant Cell Rep. 35, 1429-1438. doi: 10.1007/s00299-016-1981-3

Sternberg, S. H., Redding, S., Jinek, M., Greene, E. C., and Doudna, J. A. (2014). DNA interrogation by the CRISPR RNA-guided endonuclease Cas9. Nature 507, 62-67. doi: 10.1038/nature13011

Szittya, G., and Burgyán, J. (2013). RNA interference-mediated intrinsic antiviral immunity in plants. Curr. Top. Microbiol. Immunol. 371, 153-181. doi: 10.1007/ 978-3-642-37765-5_6

Takenaka, K., Koshino-Kimura, Y., Aoyama, Y., and Sera, T. (2007). Inhibition of tomato yellow leaf curl virus replication by artificial zinc-finger proteins. Nucleic Acids Symp. Ser. (Oxf.) 51, 429-430. doi: 10.1093/nass/nrm215

Tebas, P., Stein, D., Tang, W. W., Frank, I., Wang, S. Q., Lee, G., et al. (2014). Gene editing of CCR5 in autologous CD4 T cells of persons infected with HIV. N. Engl. J. Med. 370, 901-910. doi: 10.1056/NEJMoa1300662

Townsend, J. A., Wright, D. A., Winfrey, R. J., Fu, F., Maeder, M. L., Joung, J. K., et al. (2009). High-frequency modification of plant genes using engineered zinc-finger nucleases. Nature 459, 442-445. doi: 10.1038/nature 07845

Urnov, F., Rebar, E. J., Holmes, M. C., Zhang, H. S., and Gregory, P. D. (2010). Genome editing with engineered zinc finger nucleases. Nat. Rev. Genet. 11, 636-646. doi: 10.1038/nrg2842

Voytas, D. F. (2013). Plant genome engineering with sequence-specific nucleases. Annu. Rev. Plant Biol. 64, 327-350. doi: 10.1146/annurev-arplant-042811105552

Waltz, E. (2016). Gene-edited CRISPR mushroom escapes US regulation. Nature 532:293. doi: 10.1038/nature.2016.19754 
Wang, Y., Cheng, X., Shan, Q., Zhang, Y., Liu, J., Gao, C., et al. (2014). Simultaneous editing of three homoeoalleles in hexaploid bread wheat confers heritable resistance to powdery mildew. Nat. Biotechnol. 32, 947-951. doi: 10. $1038 /$ nbt. 2969

Wani, S., and Sanghera, G. S. (2010). Genetic engineering for viral disease management in plants. Not. Sci. Biol. 2, 20-28. doi: 10.15835/nsb.2.1.3614

Wilson, R. C., and Doudna, J. A. (2013). Molecular mechanisms of RNA interference. Annu. Rev. Biophys. 42, 217-239. doi: 10.1146/annurev-biophys083012-130404

Wolt, J. D., Wang, K., and Yang, B. (2015). The regulatory status of genome-edited crops. Plant Biotechnol. J. 14, 510-518. doi: 10.1111/pbi.12444

Woo, J. W., Kim, J., Kwon, S. I., Corvalán, C., Cho, S. W., Kim, H., et al. (2015). DNA-free genome editing in plants with preassembled CRISPRCas9 ribonucleoproteins. Nat. Biotechnol. 33, 1162-1164. doi: 10.1038/nbt. 3389

Wyman, C., and Kanaar, R. (2006). DNA double-strand break repair: all's well that ends well. Annu. Rev. Genet. 40, 363-383. doi: 10.1146/annurev.genet.40. 110405.090451

Xie, K., Minkenberg, B., and Yang, Y. (2015). Boosting CRISPR/Cas9 multiplex editing capability with the endogenous tRNA-processing system. Proc. Natl. Acad. Sci. U.S.A. 112, 3570-3575. doi: 10.1073/pnas.142029 4112
Xing, H. L., Dong, L., Wang, Z. P., Zhang, H. Y., Han, C. Y., Liu, B., et al. (2014). A CRISPR/Cas9 toolkit for multiplex genome editing in plants. BMC Plant Biol. 14:327. doi: 10.1186/s12870-014-0327-y

Ye, X. (2015). Development and application of plant transformation techniques. J. Integr. Agric. 14, 411-413. doi: 10.1016/S2095-3119(14)60945-X

Younis, A., Siddique, M. I., Kim, C. K., and Lim, K. B. (2014). RNA interference (RNAi) induced gene silencing: a promising approach of hi-tech plant breeding. Int. J. Biol. Sci. 10, 1150-1158. doi: 10.7150/ijbs. 10452

Ziebell, H. (2016). "Plant defence and viral interference," in Plant-Virus Interactions, ed. T. Kleinow (Cham: Springer International Publishing), 123-159.

Conflict of Interest Statement: The authors declare that the research was conducted in the absence of any commercial or financial relationships that could be construed as a potential conflict of interest.

Copyright (C) 2017 Romay and Bragard. This is an open-access article distributed under the terms of the Creative Commons Attribution License (CC BY). The use, distribution or reproduction in other forums is permitted, provided the original author(s) or licensor are credited and that the original publication in this journal is cited, in accordance with accepted academic practice. No use, distribution or reproduction is permitted which does not comply with these terms. 